\title{
Banking Supervision: Quality and Governance
}

\author{
Marco Arnone, Salim M. Darbar, and \\ Alessandro Gambini
}





\title{
IMF Working Paper
}

\author{
Monetary and Capital Markets Department
}

\section{Banking Supervision: Quality and Governance}

Prepared by Marco Arnone, Salim M. Darbar, and Alessandro Gambini ${ }^{1}$

Authorized for distribution by Daniel Hardy

\section{April 2007}

\begin{abstract}
This Working Paper should not be reported as representing the views of the IMF.

The views expressed in this Working Paper are those of the author(s) and do not necessarily represent those of the IMF or IMF policy. Working Papers describe research in progress by the author(s) and are published to elicit comments and to further debate.
\end{abstract}

This paper examines the relationship between the quality of banking supervision and governance of the supervisory agency, based on assessments of the Basel Core Principles and the IMF Code on Transparency in Financial Policies, covering 116 and 53 countries, respectively, with 51 common to both. We find a positive correlation between the transparency of the supervisor and the effectiveness of banking supervision; moreover, better accountability and integrity practices of the banking supervisors are associated with higher independence, which in turn is associated with better compliance with the Basel Core Principles. These results are largely robust to different stages of financial development.

JEL Classification Numbers: G28, G21, E58

Keywords: Bank supervision, governance, Basel Core Principles, transparency, accountability Author's E-Mail Address:marco.arnone@gmail.com, sdarbar@imf.org, a.gambini@univpm.it

\footnotetext{
${ }^{1}$ Catholic University (Milan, Italy) and Centre for Macroeconomics and Finance Research (CeMaFiR); IMF Monetary and Capital Markets Department; and Universita' Politecnica delle Marche (Ancona, Italy) and CeMaFiR, respectively. This project was started when Marco Arnone was at the IMF Monetary and Financial Systems Department. We would like to thank Stefano Bosi, Martin Čihák, Michele Fratianni, Donato Masciandaro, Marc Quintyn, Luca Papi, Martin Sommer, Mary Zephirin, and participants at the European Conference on Financial Regulation and Supervisions (Bocconi University, Milan, 29-30 May 2006) and at an IMF seminar for their valuable suggestions and comments. Opinions expressed and errors are ours alone.
} 
II. The Three Main Components of Regulatory Governance …….............................................5

III. International Codes on Banking Supervision: A Qualitative Analysis...............................6

A. Basel Core Principles for Effective Banking Supervision .......................................

B. IMF Transparency Code on Banking Supervision................................................12

C. Basel Core Principles and Transparency Indices in Banking Supervision ..............16

IV. Regulatory Governance and the Quality of Banking Supervision....................................19

A. Independence and Basel Core Principles ..............................................................19

B. Transparency and Basel Core Principles..........................................................22

C. Transparency in Accountability and Integrity and Basel Core Principles ..............24

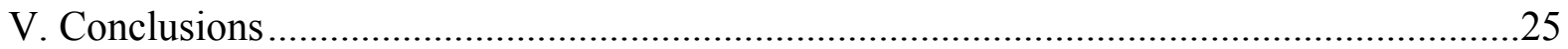

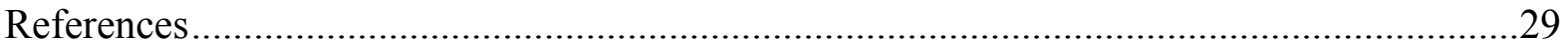

Tables

1. BCP with the Highest Proportion of Compliant and Non-compliant Assessments..............11

2. Number of Not Applicable Basel Core Principles .........................................................12

3. Not Applicable/Not assessed Transparency Practices ........................................................13

4. Cross-Country Means and Standard Deviations for Normalized BCP and Transparency

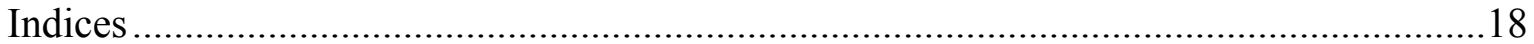

5. Correlation Coefficients between Basel CP 1 and Other Chapters.......................................20

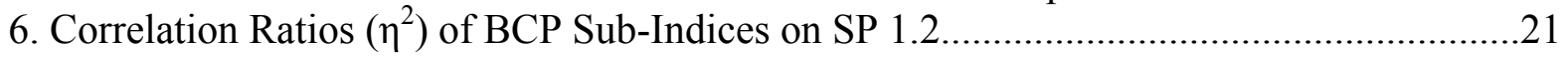

Figures

1. Compliance of Regulatory Standards for Effective Banking Supervision (BCP) ..................

2. Cross-Country Compliance of BCP by Stage of Financial Sector Development, Geographic, Area, and Income Level

3. Observance of Transparency Practices in Banking Supervision ..........................................14

4. Transparency Observance for Country Groups by Stage of Financial Sector Development, Geographic Area, and Income Level..........................................................15

5. Country Group Means and Variability of the BCP and Transparency Indices.....................17

6. Interdependence of BCP and Transparency Indicators in Banking Supervision .................23

7. Interdependence of $\mathrm{BCP}$ and Transparency in Accountability Indices ...............................25

Appendix

I. Construction of Indices of Compliance/Observance for BCP and MFP Transparency

Code in Banking Supervision 


\section{INTRODUCTION}

The question of regulating public utilities and other economic sectors, where the existence of externalities requires sector-specific supervision, raises the issue of public sector governance. The importance of public sector governance arises from the negative consequences of bad governance. The lack of resource management skills in public agencies can hinder the implementation of sound policies and result in misallocation of resources and adverse externalities. Also, governments have a monopoly power over the public sector, and hence the potential to abuse this power. The potential for abuse or corruption includes both state capture - where the interests of a political group/party are served instead of the public's and regulatory capture - where the interests of the industry are served at the expense of the consumers. $^{2}$

Regulatory and supervisory governance in the finance sector can be considered as a more specific concept of public sector governance (Das and Quintyn, 2002). The transformation of the financial landscape through liberalization, innovation and globalization of markets, and the general concern for the health of the global banking and financial markets have produced a growing consensus that the development of standards and codes of best practice can improve financial system integrity and stability. The first initiative in this sense was set up in 1997 by the Basel Committee on Banking Supervision.

Good regulatory governance in the financial and banking sector has received considerable attention in the recent past, but the empirical evidence on how it affects banking sector performance and stability is still limited. ${ }^{3}$ Evidence of the effect of supervisory independence on the quality of banking supervision is absent in the literature. Our analysis aims at investigating the relationship between the components of regulatory governance and the quality of banking supervision.

This paper presents an analysis of compliance with the Basel Committee's Core Principles for Effective Banking Supervision (BCP) and IMF Code of Good Practices on Transparency in Monetary and Financial Policies (MFP Transparency Code), and then investigates the relationship between regulatory governance — proxied by indices representing its three main components: independence, accountability (together with integrity) and transparency — and the quality of banking supervision. Key findings include:

\footnotetext{
${ }^{2}$ See Stigler (1971) and Hardy (2006) for a detailed analysis of regulatory capture in general and in the banking sector, respectively. Also, see Arnone and Iliopulos (2007) for an analysis of corruption.

${ }^{3}$ Barth, Caprio, and Levine (2001a, 2001b and 2005) use a survey on bank regulation and supervisory practices for 107 countries for the period 1998-2000 and find that greater supervisory independence is positively linked with less corruption and bank development. Using the same database, Beck, Demirguc-Kunt, and Levine (2003) highlight firm reliance on special connections and the existence of bank corruption to get external funding in those countries with strong official supervisory agencies, which have the authority to directly intervene in banks. Das, Quintyn, and Chenard (2004) use an index of regulatory governance derived from assessments undertaken as part of the FSAP to show the strong and direct impact of regulatory governance on financial system stability and soundness.
} 
- Banking supervisors' compliance with the operational independence principle was found to be among the least fully compliant principle assessed;

- There are substantial weaknesses in the area of banking supervisors' preventive and remedial powers;

- Transparency requirements are easier and cheaper to fulfill than BCP requirements, thus helping resource-constrained developing countries fulfill best international transparency practices;

- There is a positive correlation between the transparency of the supervisor and the effectiveness of banking supervision;

- Better accountability and integrity practices of the banking supervisors are associated with higher BCP compliance, especially in countries where a higher degree of supervisory independence exits;

- Europe and Central Asia score the highest in the BCP and transparency assessments, owing in part to the excellent performance of several transition economies in the European Union accession process. South East Asia and the Pacific shows above average compliance in both remedial measures for banks not meeting the requirements and in making financial policies available to the public; such compliance is consistent with reforms to strengthen supervisory agencies sanctioning powers and improve transparency following the 1997-98 financial crisis.

We consider the assessments of countries' compliance with the BCP and the MFP Transparency Code concerning banking supervision, as of end-2004. Qualitative scores have been mapped on a 4-point scale as a quantitative measure of the degree of compliance. The databases include 116 and 53 assessments for the BCP and the MFP Transparency Code, respectively, with 51 countries being common to both databases.

The rest of the paper is organized as follows: Section II describes the three main components of regulatory governance. Section III presents the empirical analysis of compliance using the indices on banking supervision based on the formal assessments of the BCP and the MFP Transparency Code under the FSAP program. Section IV focuses on the relationship between regulatory governance and the quality of banking supervision by measuring the positive "association" between (various components of) the BCP and transparency indices. Section V concludes. 


\section{The Three MaIn Components of Regulatory Governance}

Three main components of good regulatory governance in the financial sector are considered as prerequisites to regulatory/supervisory agencies' (RSA) successful regulation/supervision of financial institutions or activities: independence, accountability and transparency. ${ }^{4}$

Independence of the RSA refers to the degree to which they are insulated from, and hence able to resist, inappropriate interference both from the political sphere and from the supervised entities (financial services industry) in order to take decisions belonging to their sphere of competence without undue outside meddling. Such independence constitute a key element in achieving and maintaining the objective of financial sector stability.

Quintyn and Taylor (2002) distinguish between goal independence and instrument independence. The former is defined as the possibility to pursue the objective (usually fixed by law) that the RSA has to achieve - systemic stability, prudential oversight, conduct of business regulation and consumer protection. Instrument independence is the formulation and execution of regulatory and supervisory policies. Four dimensions of instrument independence are then classified: regulatory, supervisory, institutional and budgetary independence. Regulatory and supervisory independence are the core dimensions of instrument autonomy, while institutional and budgetary independence provide the operational arrangements necessary to support the correct implementation of the core functions.

Accountability of the RSA is the degree to which these independent agencies are responsible for their own actions, decisions and performances and are required to explain and justify them to the institutions that delegated authority to them, and to market participants. The concept of accountability goes beyond the idea of checking the supervisor's performance, because it entails also the ideas of making amends for any fault and damage and taking measures in order to avoid its recurrence. Accountability can imply the duty of periodic reporting of information, appearances before parliament and other entities, external representation in the supervisory board, internal inspectorate, and financial audit.

As in the case of central bank (CB) accountability ${ }^{5}$, there is growing interest in RSA accountability. As Hüpkes, Quintyn, and Taylor (2005) underline, the case of RSA accountability is much more complex than that of $\mathrm{CB}$ accountability with the main differences being: (i) unlike most CB, RSA are likely to have multiple objectives (including consumer protection and conduct of business regulation), which are not easy to measure;

\footnotetext{
${ }^{4}$ Das and Quintyn (2002) identify a fourth component of good corporate governance: integrity. It refers to those mechanisms ensuring that the pursuit of institutional goals is not jeopardized by the self-interested behavior of staff. Unlike the other three components, which are elements of outside governance with the relationship being between the agency and the external world, this can be considered an element of internal governance, since it concerns the internal agency's procedures. We do not analyze integrity separately, but we refer to it along with accountability since the two elements are considered together in practice 8 of the MFP Transparency Code.

${ }^{5}$ See, among others, Briault, Haldane, and King (1996), Eijffinger and de Haan (1996), Lybek (1998), De Haan, Amtenbrink, and Eijffinger (1999), and Eijffinger, Hoeberichts, and Schaling (2000).
} 
(ii) supervising the financial sector implies a degree of confidentiality in order not to undermine public confidence in commercial institutions; (iii) RSA are responsible not only to the institution from which they receive the mandate, but to a wider set of interests, including those of the supervised entities, peer jurisdictions and the public in general; and (iv) RSA are given broad regulatory and sanctioning powers which provide them with "the coercive power of the state against the private citizen" (Lastra and Wood, 1999), like revoking bank licenses.

Transparency of the RSA is a measure of the degree to which the information about its official activities (objectives, legal, institutional and economic framework, decisions, actions, practices, data and information over the regulatory and supervisory policies and the accountability of the senior executives) is constantly verifiable and communicated to the interested parties on a timely basis.

According to Sundararajan, Das, and Yossifov (2003), a transparent framework in the regulatory and supervisory policies of the financial sector requires three basic components regarding which information disclosure is needed: (i) clarity of roles, responsibilities and objectives and periodic explanation of the agencies' performance in regard to the latter, (ii) a well-founded legal, institutional and economic framework, and (iii) the provision of data and information to create an informed view on financial policies. Transparency, with its related disclosure practices, applies to all financial institutions, including supervisory authorities, which are considered an integral part of the financial sector.

The three components of regulatory governance are related to one another. The traditional approach to accountability depicted a trade-off between independence and accountability, while Quintyn and Taylor (2002) were the first to maintain that there is no trade-off between the two concepts, which are then complementary. Accountability arrangements provide the RSA with a strong reputation and public legitimacy, and are needed to sustain independence; the larger the extent of RSA independence the more important accountability becomes.

The relationship between accountability and transparency is related to the availability of information. Transparency is the condition in which adequate information is available, while accountability is not simply about the provision of information, but implies explaining and defending the action, decision or policy which is the object of the information. Sundararajan, Das, and Yossifov (2003) argue that a transparent environment supports the achievement of the other components of good regulatory governance: (i) accountability, by disclosing the actions and decisions of the agency to public and private interests, and (ii) independence, by highlighting the existence of any interference in the agency's conduct.

\section{International CODES ON BANKING Supervision: A Qualitative ANALYSIS}

A preliminary analysis of the qualitative data shows which practices and principles are observed the most and which countries or groups of countries comply more closely with best practices. Then, we use our two quantitative indices to measure countries' degree of compliance with the BCP and the MFP Transparency Code in the area of banking supervision and carry out a cross-country analysis of these measures concerning the quality of supervision and transparency of supervisors in the banking sector. 


\section{A. Basel Core Principles for Effective Banking Supervision}

The assessments of the Basel Committee's code for effective banking supervision can be taken to represent the quality of the existing system of regulation and supervision in the banking sector. The BCP is composed of 25 core principles $^{6}$ (with the first including 6 subprinciples) for a total of 30 assessable principles. ${ }^{\text {? }}$

The database includes 116 countries $^{8}$ and is the result of IMF and WB assessment missions from 1999 to 2004. The results indicate that, out of a total of 3,480 (116 countries times 30 assessable principles) assessable principles, 3,364 have been assessed, while 116 assessable principles have been scored as not applicable or no answer. Among the assessed principles, 38.32 percent were rated as compliant $(1,289$ out of 3,364$), 32.04$ percent largely compliant $(1,078), 22.5$ percent materially-non compliant (757), 7.14 percent non-compliant (240). This means that over 70 percent of assessed core principles have at least a largely compliant assessment.

\section{Compliance across all countries}

Figure 1 looks at the degree of compliance with the standards inside the seven chapters of the BCP code across the full sample. Compliance with the preconditions for effective banking supervision (chapter 1), contributing to the development of a framework of clear objectives, operational independence from political pressure and accountability for reaching them, is very high: the percentage of assessed principles scored as compliant or largely compliant is 76.55 percent.

An even better score ( 83.05 percent) can be observed for the practices regarding the licensing process for banks and the possibility for the banking supervisor to approve or reject significant changes in the structure of institutions' ownership (chapter 2).

\footnotetext{
${ }^{6}$ The principles are grouped into 7 chapters related respectively to: (i) CP 1: the preconditions for effective banking supervision, (ii) CP 2-CP 5: licensing process and approval for changes in banks' structure, (iii) CP6CP 15: prudential regulations and requirements, (iv) CP 16-CP 20: methods of ongoing banking supervision, (v) CP 21: information requirements, (vi) CP 22: remedial measures available to supervisors and (vii) $\mathrm{CP} 23-\mathrm{CP}$ 25: cross-border banking. Each of the 6 sub-principles of CP 1 is assessed individually for all countries. Hence, the 6 sub-principles are considered separately plus the $24 \mathrm{CP}$ from CP 2 to CP 25 together accounting for 30 assessable principles.

${ }^{7}$ The assessment of compliance with these core principles is done using a 4-point grading scale: compliant, largely compliant, materially non-compliant (if the observed deficiencies raise doubts about the ability to reach compliance, but substantive progress has been made to amend them), and non-compliant. A core principle is considered to be not applicable when a country is not materially engaged in the kind of banking business addressed by the BCP in question.

${ }^{8}$ Country groups by stage of financial markets development refer to Arnone, Laurens, and Segalotto (2006), while the classification by geographical areas and income level refers to the World Bank Group Data and Statistics: www.worldbank.org/data/countryclass/classgroup.htm.
} 
Interestingly, the two least observed chapters of the code seem to be connected. Almost 40 percent of the assessed principles for both the setting of prudential regulations and requirements (chapter 3 ) and the formal power for supervisors to take adequate measures, when banks fail to meet prudential requirements or violate any other regulation (chapter 6), were scored as materially non-compliant or non-compliant. This evidence suggests that there is still substantial room for improvement in RSA preventive and remedial powers.

Figure 1. Compliance of Regulatory Standards for Effective Banking Supervision (BCP) ${ }^{1 /}$

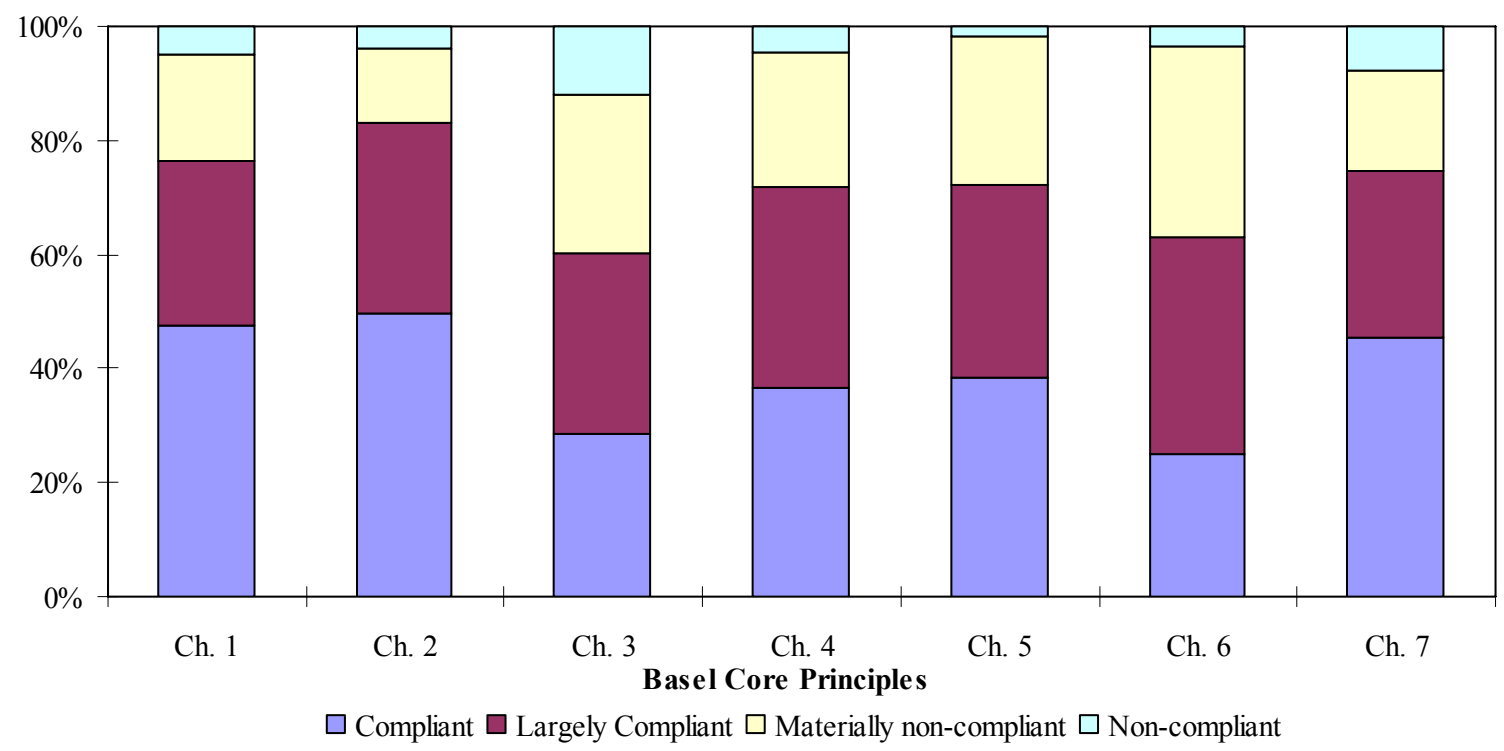

Source: authors' elaborations.

${ }^{1 /}$ Percentage refers to the number of principles categorized as compliant, largely compliant, materially noncompliant, and non-compliant over the number of principles found to be assessable and assessed.

\section{Compliance by stage of financial development}

At the top of Figure 2 we show the scores by stage of financial development: the sample includes 24 advanced countries, 26 emerging economies and 66 developing countries. The predictable existence of a decreasing trend of compliance from advanced to emerging and developing countries for all chapters is confirmed. Also, the previous findings on the pattern of strong and weak compliance are confirmed for emerging economies and developing countries. In the case of advanced countries, the chapters with highest compliance - besides chapter 7 on cross-border banking - are chapters 4 (methods of ongoing supervision) and 5 (information requirements) with degrees of compliance (compliant plus largely compliant) equal to 95.62 and 100 percent respectively, suggesting that strong financial market development proceeds in parallel with a high level of supervision and information requirements. 
Figure 2. Cross-Country Compliance ${ }^{1 /}$ of BCP by Stage of Financial Sector Development, Geographic, Area, and Income Level ${ }^{2 /}$
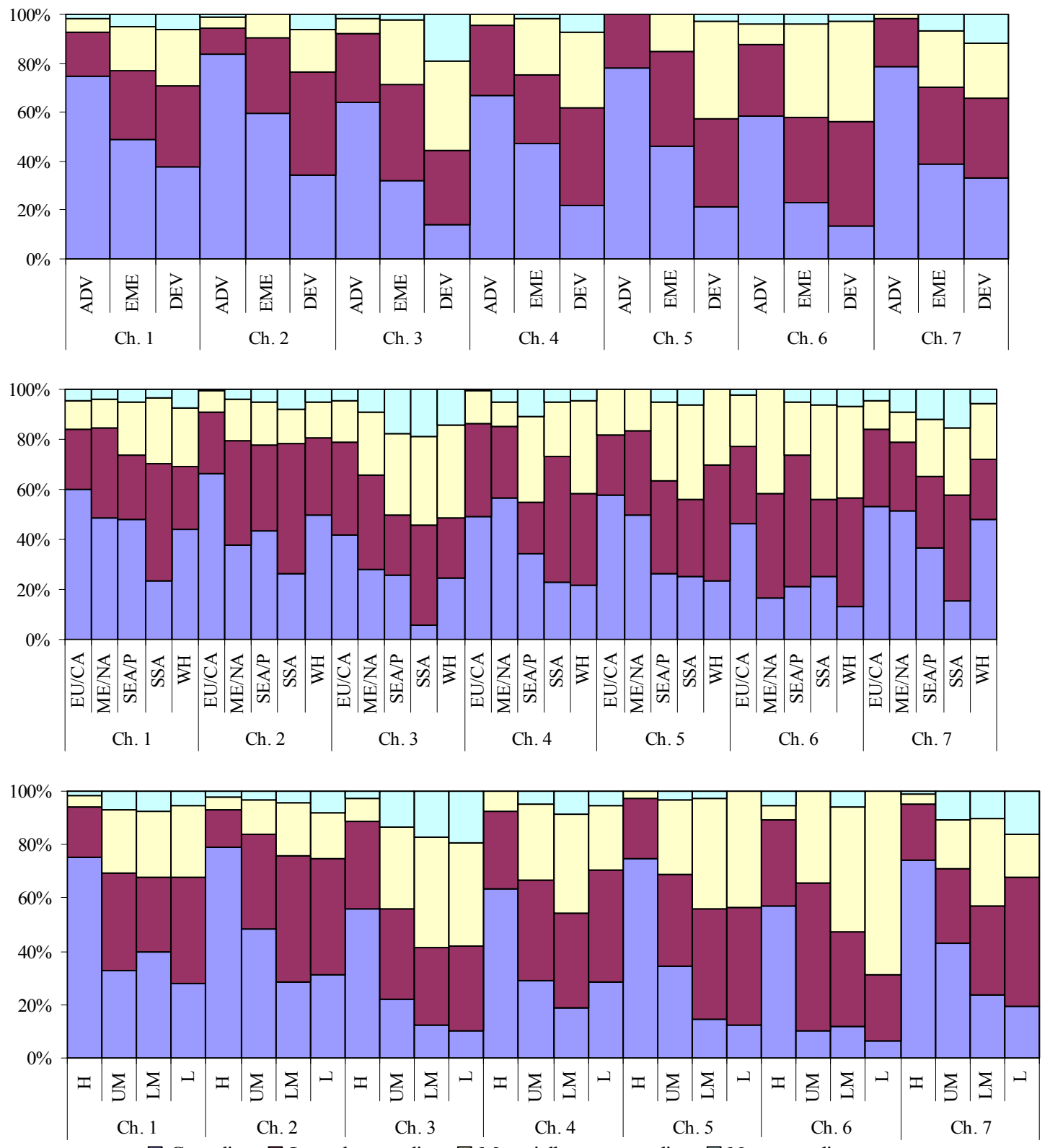

$\square$ Compliant $\square$ Largely compliant $\square$ Materially non-compliant $\square$ Non-compliant

Source: authors' elaborations.

${ }^{1 /}$ Percentage refers to the number of principles categorized as compliant, largely compliant, materially noncompliant, and non-compliant over the number of principles found to be assessable and assessed.

${ }^{2 /} \mathrm{ADV}=$ Advanced, $\mathrm{EME}=$ Emerging, $\mathrm{DEV}=$ Developing, $\mathrm{EU} / \mathrm{CA}=$ Europe and Central Asia, $\mathrm{ME} / \mathrm{NA}=\mathrm{Middle}$ East and North Africa, SEA/P=South-East Asia and Pacific, SSA=Sub-Saharan Africa, WH=Western Hemisphere, $\mathrm{H}=$ High income, $\mathrm{UM}=$ Upper middle income, $\mathrm{LM}=$ Lower Middle Income, $\mathrm{L}=\mathrm{Low}$ income. 


\section{Compliance by geographic area}

In terms of geographic area, 39 countries are in Europe and Central Asia, 12 in the Middle East and North Africa, 19 in South-East Asia and the Pacific, 16 in Sub-Saharan Africa and 30 in the Western Hemisphere. The grouping by geographic area highlights a general trend for Europe and Central Asia to be the geographical area with the highest degree of compliance, with the Middle East and North Africa not so far behind and even better in 2 cases (chapters 1 and 5), suggesting the relevance of financial resources, largely available in these 2 areas, to achieve an acceptable quality of banking supervision. The other three areas show quite a homogeneous degree of compliance in all chapters, except chapter 6 (existence of remedial measures for banks not meeting requirements) where South-East Asia and the Pacific achieves 73.68 percent of compliant and largely compliant assessments, probably owing to stronger sanctioning powers given to bank supervisors after the 1997-98 financial crisis.

\section{Compliance by income level}

Grouping countries by income level, we have 37 high-income countries, 29 upper middleincome countries, 34 lower middle-income countries, 16 low-income countries. This classification provides a further suggestion of the positive correlation between availability of resources and quality of banking supervision, given a gap of 30-40 percent in the degree of full compliance between high-income and non-high-income economies.

\section{Selected characteristics of compliance rates}

The analysis of the proportions of compliance and non-compliance for the single core principles corroborates some of the above findings. Table 1 shows the five core principles with the highest number of compliant and non-compliant assessments in the sample of 116 countries. The $\mathrm{CP}$ with the highest percentage of compliance belong to chapters 1 and 2 , while four of the five $\mathrm{CP}$ with the largest number of non-compliant assessments belong to chapter 3 .

The weak compliance with CP 11, 12, 13 (monitoring and control of financial risks) is worrying in light of the new Basel Capital Accord at the end of 2006, which entails even greater responsibilities for supervisors in order to evaluate banks' internal capital assessment processes. Urgent action is also needed to address the weaknesses in money laundering $(\mathrm{CP}$ 15), and consolidated supervision (CP 20) for the emergence of financial conglomerates and the blurring of boundaries between financial products and markets.

The majority of countries are compliant with most of the elements of CP 1, but two additional comments have to be made regarding CP 1 that are not evident from Table 1 . If we take into account only fully compliant and non-compliant assessments the data show that: (i) CP 1.2 concerning operational supervisory independence is the one with the lowest number of fully compliant assessments (31 out of 116) among the six components of CP 1 and would appear in sixth place for non-compliance in Table 1; and (ii) CP 1.5 requiring adequate legal protection for supervisors is at the same time the component with the second and third 
highest numbers of fully compliant (63) and non-compliant (19) assessments, respectively, across the sample.

Table 1. BCP with the Highest Proportions of Compliant and Non-Compliant Assessments ${ }^{1 /}$

\begin{tabular}{|c|c|c|c|}
\hline & Core Principles (chapter) & $\begin{array}{c}\# \\
\text { compliant }\end{array}$ & $\begin{array}{l}\text { \# non- } \\
\text { compliant }\end{array}$ \\
\hline 2 & Definition of permissible activities to banking institutions (2) & 111 & \\
\hline 1.1 & Clear objectives and responsibilities for supervisory agency (1) & 103 & \\
\hline 1.3 & Existence of legal framework for banking supervision (1) & 101 & \\
\hline 3 & $\begin{array}{l}\text { Licensing authority having the right to set criteria for licensing banks } \\
\text { (2) }\end{array}$ & 94 & \\
\hline 4 & $\begin{array}{l}\text { Power for supervisors to reject significant transfers of ownership in } \\
\text { banks (2) }\end{array}$ & 93 & \\
\hline 12 & Banks having systems to measure, monitor and control market risk (3) & & 61 \\
\hline 11 & $\begin{array}{l}\text { Banks having policies for identifying and managing country and } \\
\text { transfer risk (3) }\end{array}$ & & 57 \\
\hline 13 & $\begin{array}{l}\text { Banks having systems to measure, monitor and control all other } \\
\text { material risk (3) }\end{array}$ & & 55 \\
\hline 15 & Setting of rules for the prevention of fraud and money laundering (3) & & 52 \\
\hline 20 & $\begin{array}{l}\text { Ability of supervisors to oversee banking groups on a consolidated } \\
\text { basis (4) }\end{array}$ & & 51 \\
\hline
\end{tabular}

Source: authors' elaboration.

${ }^{1 /}$ Measured as the number of compliant (fully compliant and largely compliant) and non-compliant (materially non-compliant and non-compliant) scores over the full sample of 116 assessments.

These sub-principles have been already indicated as weak in the IMF-WB (2002) review of BCP implementation, although based on a small sample of countries; this means that independence and legal protection for bank supervisors are still not completely established all over the world, because these are some areas where efficient action in banking supervision is often overturned by political interference and weak court systems.

We should also mention those cases when the assessors have considered a core principle not to be applicable to the banking system of a country, basically because the country is not materially engaged in the kind of banking business addressed by the CP in question. Table 2 shows that more than 60 percent of the economies ( 72 out of 116) present 0 not applicable $\mathrm{CP}$; the number of not applicable assessments ranges from 1 to 4 in the remaining part of the sample, except for 2 cases, one of which appears to be an outlier because $22 \mathrm{CP}$ out of 30 were assessed as not applicable.

The country grouping indicates that not applicable assessments are basically concentrated in developing countries. Among the highest number of not applicable assessments, CP 20 (conduct of consolidated supervision), CP 23 (global consolidated supervision over internationally active banks) and CP 24 (information exchange with other with other supervisors) received respectively 18, 25, and 34 not applicable assessments, reflecting that 
banks from developing countries are not as active internationally compared with those from developed ones. The majority of the remaining principles and sub-principles (23 out of 30) received 0 or 1 not applicable assessment.

Table 2. Number of Not Applicable Basel Core Principles

\begin{tabular}{lccccccccc}
\hline & \multicolumn{7}{c}{ Number of not applicable assessments } & \\
\cline { 2 - 7 } & 0 & 1 & 2 & 3 & 4 & 5 & $>5$ & \\
\hline Overall sample & 72 & 14 & 14 & 9 & 5 & 1 & 1 & 116 \\
Advanced countries & 20 & 2 & 1 & 0 & 0 & 0 & 1 & 24 \\
Emerging countries & 22 & 4 & 0 & 0 & 0 & 0 & 0 & 26 \\
Developing countries & 30 & 8 & 13 & 9 & 5 & 1 & 0 & 66 \\
& & & & & & & & \\
Europe \& Central Asia & 30 & 3 & 4 & 1 & 0 & 0 & 1 & 39 \\
Middle East \& North Africa & 8 & 2 & 2 & 0 & 0 & 0 & 0 & 12 \\
South-East Asia \& Pacific & 11 & 5 & 0 & 1 & 1 & 1 & 0 & 19 \\
Sub-Saharan Africa & 4 & 2 & 3 & 3 & 4 & 0 & 0 & 16 \\
Western Hemisphere & 19 & 2 & 5 & 4 & 0 & 0 & 0 & 30 \\
High income & 29 & 4 & 3 & 0 & 0 & 0 & 1 & 37 \\
Upper middle income & 19 & 0 & 3 & 4 & 3 & 0 & 0 & 29 \\
Lower middle income & 19 & 7 & 5 & 2 & 0 & 1 & 0 & 34 \\
Low income & 5 & 3 & 3 & 3 & 2 & 0 & 0 & 16 \\
\cline { 1 - 7 } & & & & & & & &
\end{tabular}

Source: authors' elaboration.

\section{B. IMF Transparency Code on Banking Supervision}

The MFP Transparency Code assessments in banking supervision indicate the degree of transparency in the actions of agencies regulating and supervising the banking business (IMF, 1999). ${ }^{9}$ The assessment of observance with the transparency practices is carried out using a 4-point grading scale. ${ }^{10}$ As of end-2004 the MFP Transparency Code database

\footnotetext{
${ }^{9}$ The MFP Transparency Code contains transparency practices for seven different policy functions: monetary policy and 6 financial policies: banking supervision, deposit insurance, insurance regulation, payment systems oversight, securities regulation and other (including asset management, debt restructuring, futures and option oversight, and pension funds oversight). The MFP Transparency Code is divided into 8 main practices.

Practices 1 to 4 deal with transparency in monetary policies while practices 5 to 8 deal with transparency in financial policies. Thus this paper deals with practices 5 to 8: practice 5, clarity of roles, responsibilities and objectives of financial agencies; practice 6 , the processes for formulating and reporting of financial policies; practice 7 , public availability of information on financial policies; and practice 8 , accountability and assurances of integrity by financial agencies. Practices 5 to 8 consist of 36 assessable components, which are referred to as practices. See IMF (1999) for details.

${ }^{10}$ The four grades are: fully observed, broadly observed, partially observed and not observed. Transparency practices are considered to be not applicable or not assessed when a country is not materially engaged in the kind of banking business addressed by the practice in question.
} 
contained finalized assessments for transparency practices for banking supervision for 53 countries, 51 of which were in common with the BCP database.

A much larger number of practices than in the case of the BCP have been reported as not applicable or not assessed: 469 out of 1,908 (36 times 53) assessable practices - almost 9 on average per country versus 1 per country for the BCP, with 2 countries from the Middle East and North Africa and 1 from South-Asia receiving respectively 20,17 and 18 not applicable/not assessed scores. Table 3 reports the seven practices assessed as not applicable or not assessed in two thirds of countries or more. The insufficient development of the financial sector would seem to be the origin of the non-applicability of those practices which all deal with transparency in payment systems, deposit insurance and consumer protection.

Table 3. Not Applicable/Not Assessed Transparency Practices

\begin{tabular}{|c|c|c|}
\hline & Transparency practices & $\begin{array}{l}\text { \#not ass./ } \\
\text { not appl. }\end{array}$ \\
\hline 5.3 & Public disclosure of the role of oversight agencies on payment systems & 46 \\
\hline 5.3 .1 & $\begin{array}{l}\text { Disclosure of general policy principles affecting robustness of payment } \\
\text { systems }\end{array}$ & 48 \\
\hline 5.4 & Disclosure of relationship between agencies overseeing payment systems & 43 \\
\hline 5.5 & $\begin{array}{l}\text { Enforcement to self-regulatory organizations of the same transparency } \\
\text { Practices specified for financial agencies }\end{array}$ & 44 \\
\hline 6.1 .3 & Public disclosure of the regulations for the operation of organized markets & 36 \\
\hline 7.6 & $\begin{array}{l}\text { Public disclosure of information on deposit insurance guarantees, if } \\
\text { applicable }\end{array}$ & 38 \\
\hline 7.7 & Transparency on consumer protection arrangements & 35 \\
\hline
\end{tabular}

Source: authors' elaboration.

Another difference from the BCP database is the very high percentage of fully observed practices among the assessed ones -71.86 percent (1,034 out of 1,439 assessed practices) compared to 38.32 percent in the BCP case for fully compliant core principles. Therefore, transparency requirements in banking supervision are more likely to be fulfilled (and scored as fully observed) than BCP requirements, probably owing to the fact that it is easier and, above all, cheaper to disclose information than build up a regulatory framework with adequate expertise and resources to satisfy $\mathrm{BCP}$ requirements for effective banking supervision.

\section{Observance across all countries}

Figure 3 shows the aggregate proportions of observance for practices 5 to 8 of the MFP Transparency Code across the overall sample. The degree of full observance for the transparency practices is 10 percent higher in the areas of formulation and reporting of financial policies (practice 6) and making information on those policies available to the public (practice 7), than in the areas of setting clear objectives, roles and responsibilities for 
the RSA (practice 5) and accountability and assurance of integrity by financial agencies (practice 8).

Figure 3. Observance of Transparency Practices in Banking Supervision ${ }^{1 /}$

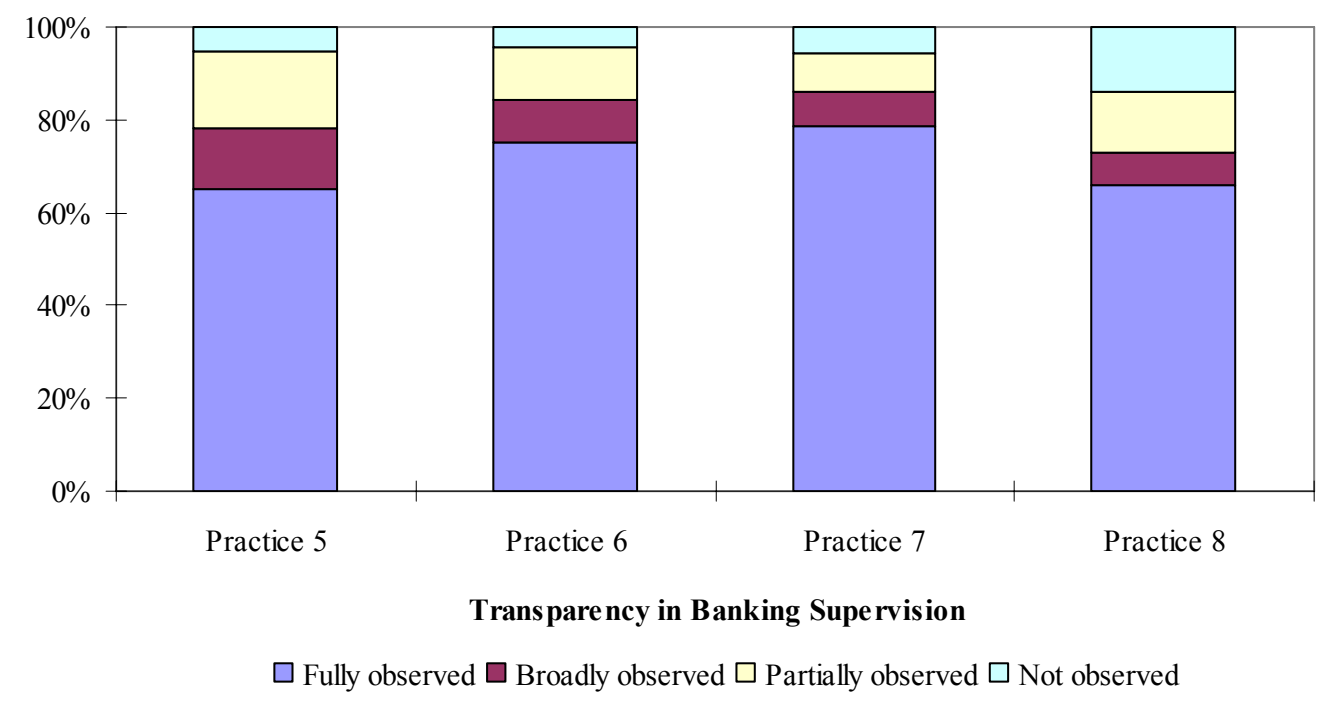

Source: authors' elaborations.

${ }^{1 /}$ In percentage of the number of assessable practices found to be applicable and assessed.

The provision of public information services (practice 7.4) and the availability of the text of regulations, directives and guidelines (practice 7.5) are particularly strong with 46 and 48 fully observed out of 53 assessments, respectively; the percentage of not observed practices for practice 8 is 13.99 percent, which is twice the average proportion of non-observance for the other three practices. This may be explained by the fact that the sample is composed of nearly 80 percent of emerging and developing countries, where even if bank supervisors are located in central banks, there is still a gap in independence and, therefore, in accountability.

Figure 4 looks at the aggregate degrees of observance across countries grouped by the same criteria as above. Across the 3 country groupings, the previous results concerning the most observed practices and the large percentage of not observed practices for practice 8 (accountability of financial agencies) are essentially confirmed, obviously with some exceptions due to the particular nature of the country groups.

\section{Observance by stage of financial development}

Within the grouping by stage of financial development, there exists an evident and foreseeable trend for advanced economies to present in all practices a higher proportion of practices assessed as fully and broadly observed than emerging economies and developing countries. The same can be argued with regard to emerging markets as compared to developing countries. 
Figure 4. Transparency Observance ${ }^{1 /}$ for Country Groups by Stage of Financial Sector Development, Geographic Area, and Income Level ${ }^{2 /}$
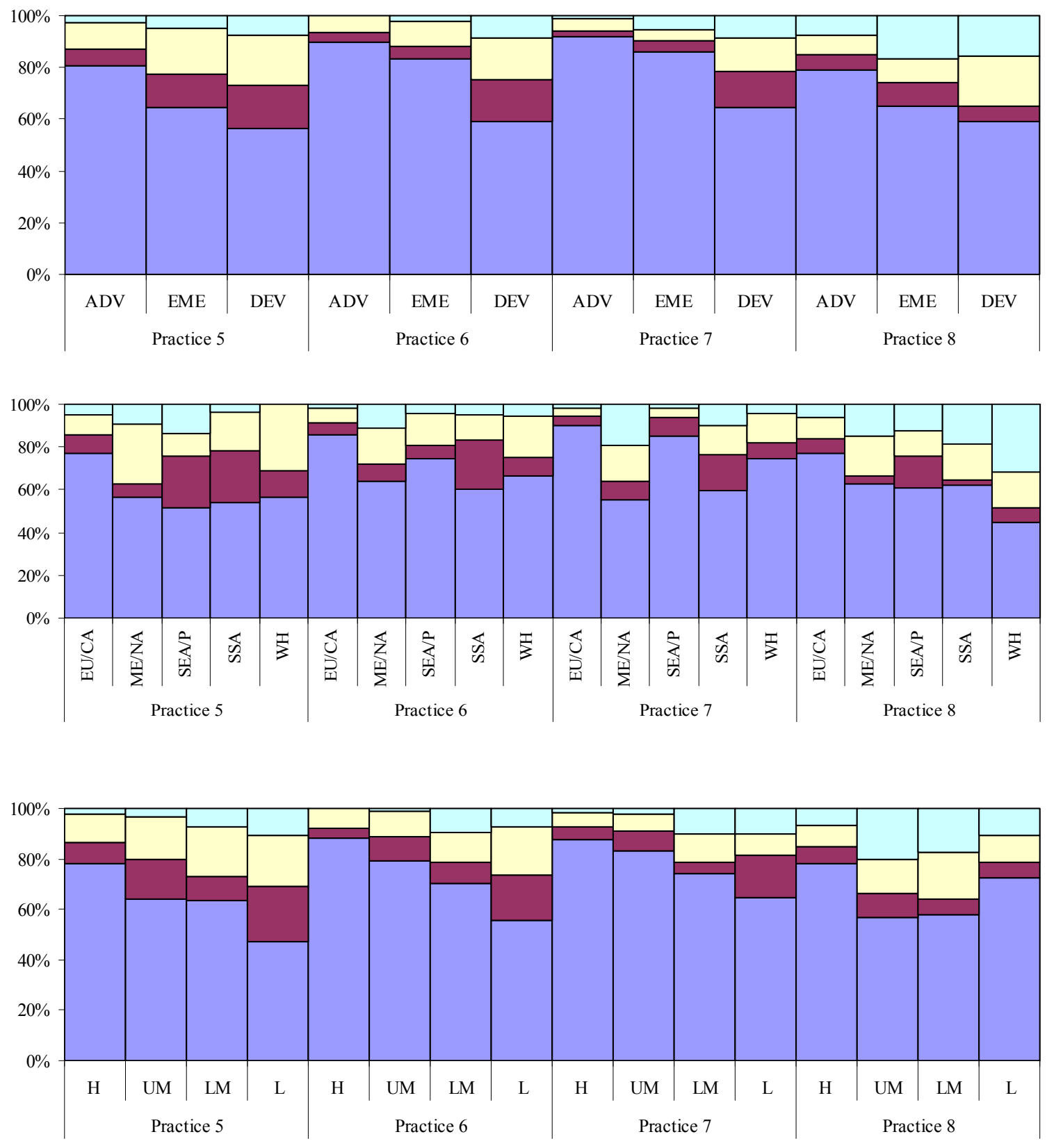

$\square$ Fully observed $\square$ Broadly observed $\square$ Partially observed $\square$ Not observed

Source: authors' calculations.

${ }^{1 /}$ Percentage refers to the number of principles categorized as compliant, largely compliant, materially noncompliant, and non-compliant over the number of principles found to be assessable and assessed.

${ }^{2 /} \mathrm{ADV}=$ Advanced, EME=Emerging, $\mathrm{DEV}=$ Developing, EU/CA=Europe and Central Asia, ME/NA=Middle East and North Africa, SEA/P=South-East Asia and Pacific, SSA=Sub-Saharan Africa, WH=Western Hemisphere, $\mathrm{H}=$ High income, $\mathrm{UM}=$ Upper middle income, $\mathrm{LM}=$ Lower Middle Income, $\mathrm{L}=$ Low income. 


\section{Observance by geographic region}

Some interesting points arise from the geographical grouping of countries: Europe and Central Asia show large proportions of full and broad observance for all practices of the code. This result may be explained by the presence in that area of a considerable number of transition economies, some of which started reforms in the process of entering the European Union.

The other groups exhibit homogeneous observance inside each of the 4 main practices. However, some peculiarities can be noticed such as the high (31.98 percent) proportion of non observance and the low (44.44 percent) proportion of full observance of transparency in accountability and integrity practices (practice 8 ) for the Western Hemisphere. Also, the high level (85.11 percent) of full observance for South-East Asia and the Pacific in making financial policies available to the public (practice 7), appears consistent with the reforms initiated to improve transparency following the 1997-98 financial crisis.

\section{Observance by income level}

The grouping by income level indicates a smaller gap between high income economies and non-high income economies than in the case of the BCP, suggesting the idea that providing a transparent supervisory setting does not seem to be resource constrained to the extent that achieving a high quality level in banking supervision does. This is supported by the fact that transparency in low-income countries is always very close to the one of upper middle- and lower middle-income countries and even higher in the case of accountability and assurance of integrity for financial agencies (practice 8).

\section{Basel Core Principles and Transparency Indices in Banking Supervision}

We have constructed two normalized indices to measure the overall degree of compliance with the (i) BCP and (ii) MFP Transparency Code in banking supervision. In both cases the value of the index for each country is the unweighted aggregation of the numerical scores associated with the qualitative assessments ${ }^{11}$ of each principle or practice, divided by its theoretical maximum ( 90 for the BCP and 108 for transparency). The minimum theoretical value is 0 .

Figure 5 compares the means and the standard deviations of the normalized indicators across countries. In almost all cases the transparency index is higher than the BCP index. Again, this result can be explained by the fact that providing transparency disclosure is cheaper than building a legal, political and social framework to achieve a high quality of banking supervision. Publishing data and periodic reports, and opening and updating websites are easier arrangements to implement than training specialized and competent staff and dealing with possible political interference.

\footnotetext{
${ }^{11}$ For a detailed description of the methodology applied to construct the indices see the Appendix.
} 
Figure 5. Country Group Means and Variability of the BCP and Transparency Indices
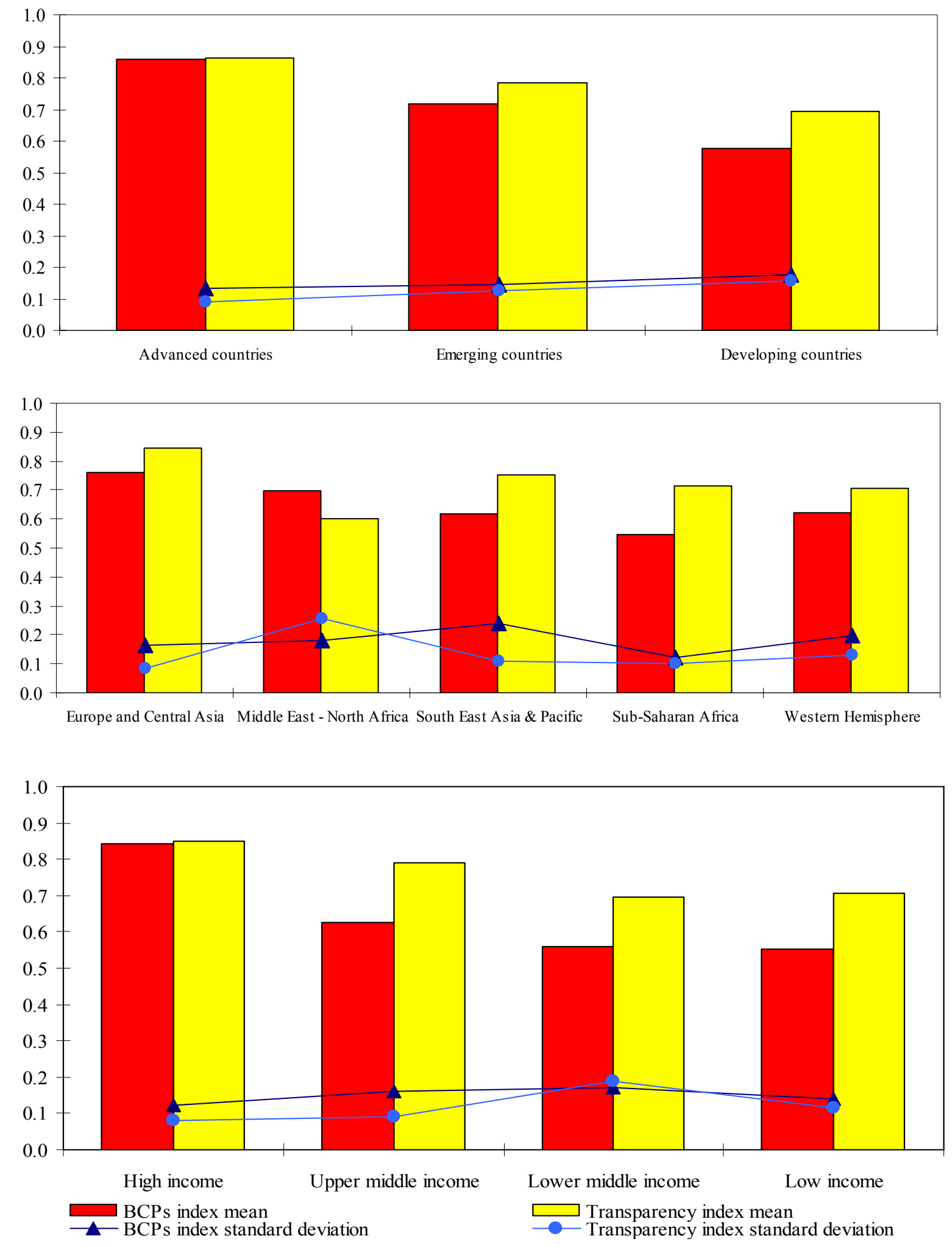

Source: authors' calculations. 
In grouping countries by stage of financial development, the average value in both cases grows with the increasing level of development, being the highest in advanced economies ( 0.86 for both BCP and Transparency Code) and the lowest in the developing countries ( 0.5753 and 0.6960 , respectively). The standard deviations also increases for both indices from advanced economies to emerging markets and further to developing countries (Table 4), suggesting a more heterogeneous supervisory environment for developing countries.

Table 4. Cross-Country Means and Standard Deviations for Normalized BCP and Transparency Indices

\begin{tabular}{lcccc}
\hline & \multicolumn{4}{c}{ Descriptive statistics } \\
\cline { 2 - 5 } & $\begin{array}{c}\text { BCP } \\
\text { Mean }\end{array}$ & $\begin{array}{c}\text { BCP } \\
\text { Standard } \\
\text { Deviation }\end{array}$ & $\begin{array}{c}\text { Transparency } \\
\text { Mean }\end{array}$ & $\begin{array}{c}\text { Transparency } \\
\text { Standard } \\
\text { Deviation }\end{array}$ \\
\hline Overall sample & 0.6660 & 0.1968 & 0.7630 & 0.1467 \\
Advanced & 0.8600 & 0.1350 & 0.8608 & 0.0902 \\
Emerging & 0.7171 & 0.1432 & 0.7828 & 0.1259 \\
Developing & 0.5753 & 0.1758 & 0.6960 & 0.1582 \\
Europe and Central Asia & 0.7621 & 0.1656 & 0.8431 & 0.0859 \\
Middle East and North Africa & 0.6985 & 0.1791 & 0.6020 & 0.2575 \\
South-East Asia & 0.6194 & 0.2374 & 0.7506 & 0.1095 \\
Sub-Saharan Africa & 0.5463 & 0.1222 & 0.7154 & 0.0993 \\
Western Hemisphere & 0.6214 & 0.1964 & 0.7071 & 0.1290 \\
High income & 0.8440 & 0.1230 & 0.8485 & 0.0852 \\
Upper middle income & 0.6259 & 0.1692 & 0.7906 & 0.0989 \\
Lower middle income & 0.5598 & 0.1729 & 0.6959 & 0.1935 \\
Low income & 0.5526 & 0.1447 & 0.7062 & 0.1240 \\
\hline
\end{tabular}

Source: authors' estimates.

With regard to geographic areas, the BCP and transparency means for Europe and Central Asia (0.76 and 0.84 , respectively) are the highest of all groups. This can be explained not only by the many highly developed countries in the group, but also by the good performance of the several Eastern European transition economies, some of which were in the process of entering the European Union at the time of the assessment and received very high scores, even above the average of highly developed economies.

Looking at other geographic areas, the BCP mean and standard deviation for Sub-Saharan Africa is the lowest among all groups, confirming the idea that good quality of supervision requires adequate financial resources and trained human capital. The Middle East and North Africa is the only group in all three classifications for which the mean of the transparency index is lower than that of the BCP index. This result, which is strongly influenced by the very low level of compliance for one country in the region, does not change even after excluding that outlier. Moreover, the standard deviation of transparency in the Middle East and North Africa is the highest among all geographical sub-samples. 
The grouping by income level corroborates the idea that higher income levels, enhancing the size of countries' financial sectors and their capability to invest financial resources in supervision practices and to train skilled staff, increases the quality of banking supervision more than the ability to fulfill transparency practices. The gap between the average degree of compliance of high income countries and non-high income countries is much higher for the $\mathrm{BCP}$ index than for the transparency index, confirming the notion that non-high income countries have the possibility of achieving a good level of transparency. High income countries, where financial resources are extensively available, constitute the only group where the BCP and transparency indices achieve almost the same degree of compliance $(0.84$ and 0.85 , respectively), while for all other income groups the observance of transparency practices is stronger than $\mathrm{BCP}$ compliance.

\section{Regulatory GovernanCE AND THE QUALITY OF BANKING SUPERVISION}

In this section we make use of the two indices described in Section III to analyze empirically the relationship existing between the quality of effective banking supervision, as expressed by the $\mathrm{BCP}$ index, and three components of regulatory governance: independence, accountability and transparency. These are included in parts of the BCP (CP 1) and of the transparency code, including especially transparency in accountability and integrity practices.

Even though the BCP code does not provide a comprehensive overview of the four components of regulatory governance (the three discussed here plus integrity), the six subprinciples (SP) of CP 1 are related to them (Das and Quintyn, 2002; Das, Quintyn, and Chenard, 2004), since, in addition to operational independence, they include governancerelated components such as the adequacy of minimum staff, resources, legal protection for the regulatory staff, a suitable legal framework connected with the enforcement powers, clarity and transparency of objectives and responsibilities with particular attention to confidentiality of shared information between supervisors. Moreover, independence, autonomy, accountability, transparency and integrity requirements are mentioned in several essential and additional criteria stated in the Core Principles Methodology (Basel Committee, 1999) that is used to assess the six SP.

The MFP Transparency Code provides a comprehensive framework of governance-related aspects of transparency. It considers not only transparency itself, but also transparency aspects of accountability and integrity. Therefore, we include a statistical analysis between different parts of the MFP Transparency Code.

\section{A. Independence and Basel Core Principles}

The only component of regulatory governance to be directly mentioned in the BCP code is independence of the regulatory agency. ${ }^{12}$ Across the 116 jurisdictions considered, SP 1.2 on

\footnotetext{
${ }^{12}$ Basel Committee (1997), SP 1.2 states that each agency involved in the supervision of banks 'should possess operational independence and adequate resources.'
} 
RSA operational independence and adequacy of resources is the least observed among the six SP regarding preconditions for effective banking supervision (CP 1) with an average normalized score of $0.61 .{ }^{13}$

The correlation between the sub-index for chapter 1 (governance) and the sub-indices for, firstly, each chapter and, secondly, the overall BCP-index-minus-chapter 1 can give some hints about the relationship between regulatory governance and the quality and effectiveness of banking supervision. This analysis is provided in Table 5 for the overall sample of countries and for the sub-samples by stage of financial development. All the correlation coefficients for the overall sample are statistically significant at the 99 percent level of confidence. A fairly strong and significant relationship exists between the chapter 1 subindex, containing $\mathrm{BCP}$ assessments related to regulatory governance, and the sub-indices of other specific chapters concerning the effectiveness of banking supervision. As expected, the correlation is at its maximum when we consider chapter 1 and the sum of the other six chapters.

Table 5. Correlation Coefficients between Basel CP 1 and Other Chapters

\begin{tabular}{lccccc}
\hline $\begin{array}{c}\text { Preconditions for effective } \\
\text { banking supervision }- \\
\text { CP 1 }\end{array}$ & Ch. 2 & Ch. 3 & Ch. 4 to 6 & Ch. 7 & $\begin{array}{c}\text { BCP minus } \\
\text { CP 1 }\end{array}$ \\
\hline & $0.5997^{* * *}$ & $0.6182^{* * *}$ & $0.6460^{* * *}$ & $0.6044^{* * *}$ & $0.6944^{* * *}$ \\
All countries & $0.3756^{*}$ & $0.4653^{* *}$ & $0.5380^{* * *}$ & $0.4723^{* *}$ & $0.5458^{* * *}$ \\
Advanced economies & $0.5224^{* * *}$ & $0.3765^{*}$ & $0.6035^{* * *}$ & $0.4729^{* *}$ & $0.5501^{* * *}$ \\
Emerging markets & $0.6001^{* * *}$ & $0.5599^{* * *}$ & $0.5581^{* * *}$ & $0.5703^{* * *}$ & $0.6566^{* * *}$ \\
\hline
\end{tabular}

Source: authors' calculations.

Symbols $*, * *, * *$ indicate statistically significant at the $90,95,99$ percent level of confidence.

The correlation between chapter 1 and the other chapters appears to be inversely related to the level of financial development, with the advanced economies exhibiting the lowest and developing countries the highest. Hence, a stronger association between the degree of compliance with chapter 1 , representing regulatory governance, and that with the other chapters, representing prudential supervision and regulatory and supervisory practices, arises for developing countries than for advanced ones. Chapters 5 and 6 have been grouped

\footnotetext{
${ }^{13}$ The normalized average for the overall chapter 1 is 0.73 . The normalized means for SP 1.2 in the sub-samples of countries in which the central bank does, and does not, have substantial powers in banking supervision are 0.63 and 0.58 , respectively. However, this difference is not statistically significant.
} 
together with chapter 4 because the sub-index for these chapters can only assume four possible scores, since these sections contain only one core principle. In such a case, the correlation coefficient could not be a correct measure of association.

The same statistical problem arises when we consider the relationship between SP 1.2 providing four possible values for operational independence and adequacy of resources for the RSA and the sub-indices for the other chapters and for BCP-index-minus-SP 1.2. In this case, an alternative computational approach to measure the association between RSA independence and other chapters of the BCP code is given by the correlation ratio $\left(\eta^{2}\right)^{14}$ measuring the mean dependence of the BCP sub-indices on SP 1.2. ${ }^{15}$ Table 6 reports the correlation ratios of BCP sub-indices on SP 1.2 for the overall sample of countries and for the sub-samples by stage of financial sector development.

Table 6. Correlation Ratios $\left(\eta^{2}\right)$ of BCP Sub-Indices on SP 1.2

\begin{tabular}{|c|c|c|c|c|c|}
\hline $\begin{array}{l}\text { Operational independence and } \\
\text { adequate resources for RSA agencies } \\
\text { - Basel SP } 1.2 \text { and }\end{array}$ & Ch. 2 & Ch. 3 & Ch. 4 to 6 & Ch. 7 & $\begin{array}{l}\mathrm{BCP} \\
\text { minus }\end{array}$ \\
\hline Overall sample & 0.1213 & 0.2091 & 0.2712 & 0.1305 & 0.2603 \\
\hline Advanced countries & 0.0256 & 0.0285 & 0.0461 & 0.0871 & 0.0559 \\
\hline Emerging countries & 0.0801 & 0.1152 & 0.3664 & 0.0921 & 0.2829 \\
\hline Developing countries & 0.1260 & 0.1878 & 0.2491 & 0.1180 & 0.2345 \\
\hline
\end{tabular}

Source: authors' calculations.

The analysis of the correlation ratios suggests the existence of a mean dependence of BCPindex-minus-SP 1.2 on operational independence and adequacy of resources for RSA (SP 1.2). In particular, on average the degree of compliance with the BCP increases when we consider increasing degrees of operational independence. The mean dependence is evident for emerging markets and developing countries, while for advanced countries, that we have shown to have the best and least volatile BCP compliance, the conditional means of the

\footnotetext{
14 The correlation ratio $\left(\eta^{2}\right)$ is used to measure the association between a truly quantitative variable and a qualitative categorized or discrete quantitative variable with few possible values. It is the ratio of the statistical dispersion within individual categories (explained variance) and the total dispersion across the whole sample (total variance). It is a normalized index with values ranging from 0 (mean independence of one variable on another) to 1 (perfect mean dependence). The correlation ratio has the advantage against the correlation coefficient not to assume a linear relationship between the two variables.

${ }^{15}$ Considering the methodology used to construct the BCP index, SP 1.2 can be considered either a discrete quantitative variable with only four values $(3,2,1$, and 0$)$ or a qualitative categorized variable, the ordered categories being compliant, largely compliant, materially non-compliant, and non-compliant.
} 
single chapters are not very much affected by the values of the SP 1.2 assessment. This suggests that a higher degree of operational independence is especially needed where the financial sector is less developed.

\section{B. Transparency and Basel Core Principles}

In this section we examine the empirical relationship between the BCP and the MFP Transparency Code. As mentioned earlier, chapter 1 of the BCP contains elements of good governance that are also evaluated under the transparency code. Thus, assessment teams generally make an effort to be consistent in their evaluation of the common aspects of the two codes. This implies that the association between the rating for BCP chapter 1 and the transparency ratings could potentially be high. However, this potential high association would only be applicable for BCP chapter 1 and the MFP Transparency Code, and not the other Basel Core Principles, since the elements evaluated under these latter principles are focused on aspects of prudential supervision. Therefore, in our empirical analysis of the relationship between quality of supervision and good governance below, we look at a subindex of the $\mathrm{BCP}$ which excludes $\mathrm{BCP}$ chapter 1 vis-à-vis the MFP Transparency Code index. ${ }^{16}$

\section{Transparency of supervisors and quality of banking supervision}

Figure 6A presents a scatter plot for the 51 countries common to both databases. The coefficient of correlation between the two indices is 0.65 for the overall sample and is statistically significant at the 99 percent level of confidence. The majority of countries are located at the top-right hand of the graph along the trend line with slope 0.97, also statistically significant at the 99 percent level.

Figure 6B plots the scores for advanced, emerging and developing countries of the two indices. The positive correlation between the BCP-minus-chapter 1 and transparency indices is confirmed within the groups. The association is strong (0.79) and significant at the 99 percent level of confidence for advanced countries. ${ }^{17}$ The interdependence of the two variables is weaker (0.29) and statistically non-significant for emerging markets and quite strong (0.55) and significant at the 99 percent level of confidence for developing countries, though lower than in the case of advanced economies. This evidence may be explained by two considerations: the higher homogeneity of developing countries and their willingness to converge as fast as possible to good practices; and the higher dispersion of emerging markets, some of which are not so far from advanced countries, while others are closer to the group of developing countries.

\footnotetext{
${ }^{16}$ All statistically significant results presented in this section are confirmed when considering the overall BCP index vis-à-vis the transparency index.

${ }^{17}$ When the sub-sample size is lower than 30 , Shapiro-Wilk tests for normality of country-groups data have always been run before testing for the significance of correlation coefficients.
} 
Figure 6. Interdependence of $\mathrm{BCP}$ and Transparency Indicators in Banking Supervision

A. Overall sample

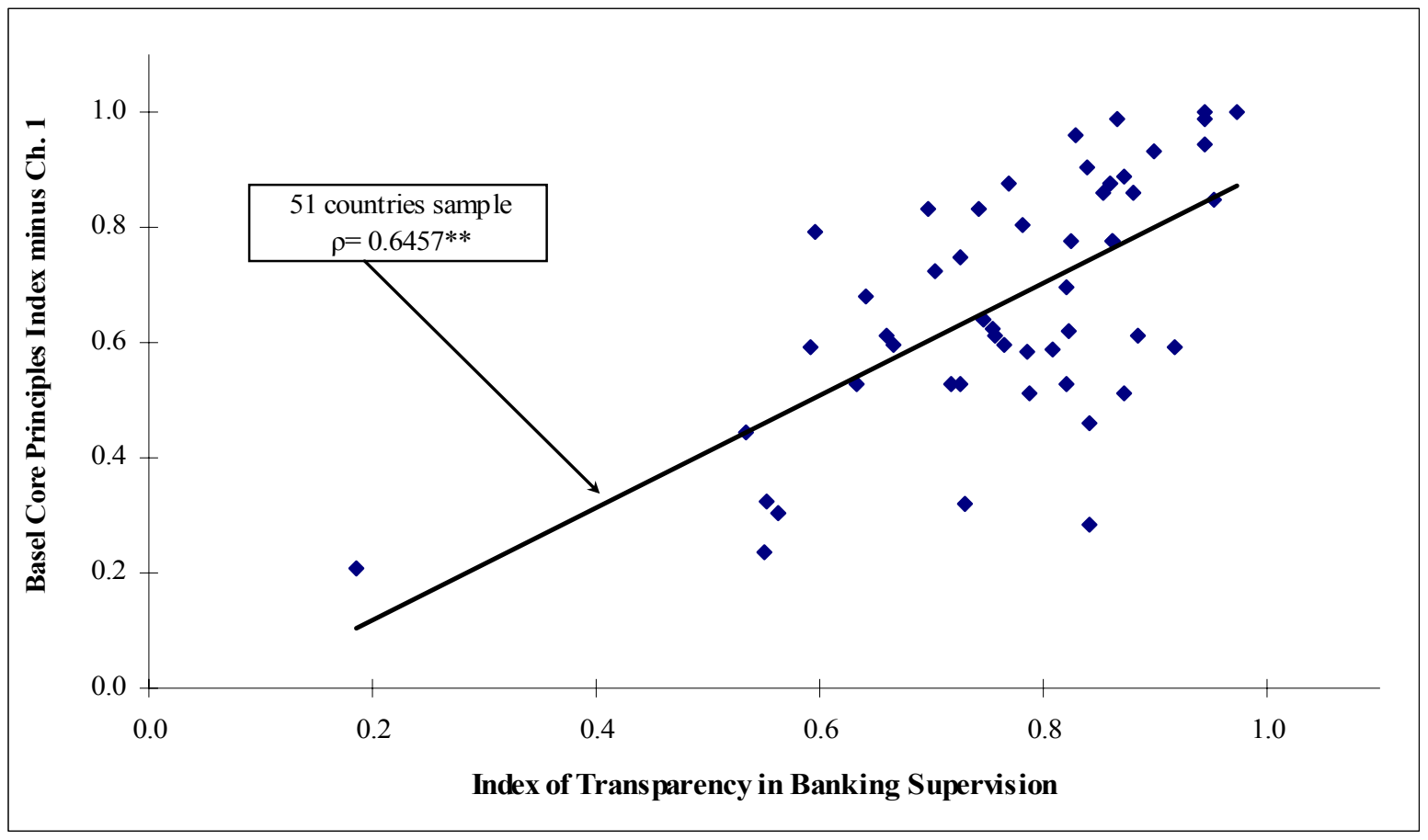

B. By Stage of Development of the Financial Sector

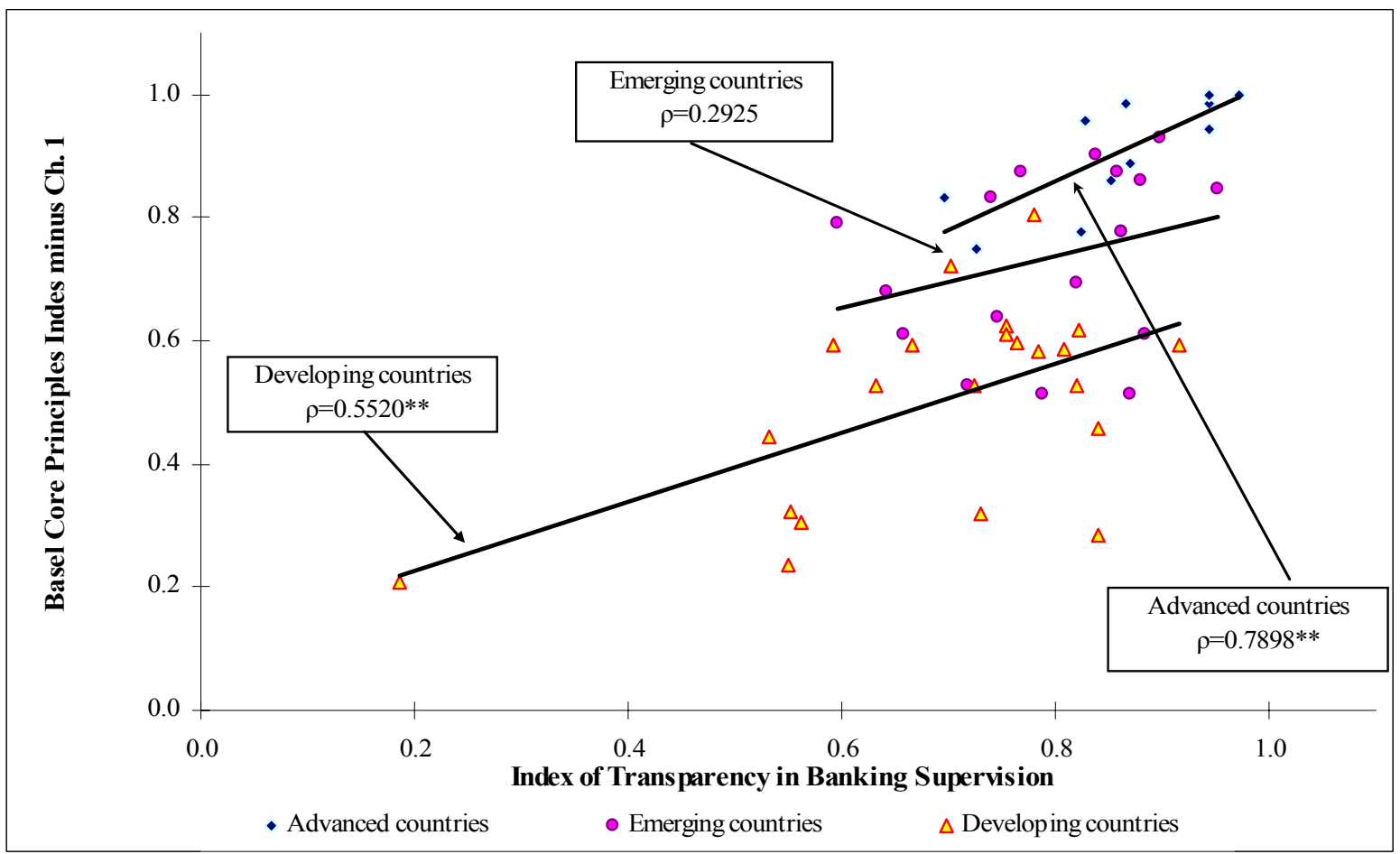

Source: authors' calculations.

*(**) Statistically significant at the 95 (99) percent level of confidence. 
The positive relationship between the two variables is preserved when we consider the two sub-samples, one in which the central bank has at least some substantial power in banking supervision, even if it does not have exclusive responsibility, and the other in which banking supervision is completely entrusted to one or more agencies outside the central bank and the central bank has no supervisory responsibility. The correlation coefficients are both positive and statistically significant, and a stronger association seems to arise when monetary and financial policies are separated (0.76) than in the case in which they are jointly entrusted to the central bank $(0.60) .{ }^{18}$

\section{Transparency in Accountability and Integrity and Basel Core Principles}

The MFP Transparency Code provides a comprehensive framework of governance-related aspects of transparency. It considers not only transparency itself, but also transparency aspects of accountability (practices 5.1.3, 6.3, 7.1, 7.3, 7.4.2, 8.1, 8.2, 8.2.1, 8.2.2, and 8.3) and integrity (practices 5.1.4, 8.4 and 8.4.1) (see Das and Quintyn, 2002). Hence, it is interesting to isolate those practices focusing just on accountability and integrity, and construct a sub-index of the MFP Transparency Code for transparency in accountability and integrity. Given the above connection between overall transparency in banking supervision and the quality of banking supervision (as expressed by the overall transparency and BCP indices, respectively), we expect a similar relationship to exist between the overall BCP index and the sub-index of transparency aspects of accountability and integrity, perhaps less strong given the low observance of practice 8 .

Figure 7 plots BCP and transparency in accountability and integrity indices. Across the overall sample the correlation coefficient is 0.57 , which is statistically significant at the 99 percent level of confidence. As shown in Figure 7, this association is very strong (0.88) and statistically significant at the 99 percent level of confidence for advanced economies, less strong and statistically significant at the 95 percent level of confidence for developing countries, and statistically not significant for emerging countries. The fact that the association is particularly strong for advanced countries, where bank supervisors usually have a higher degree of independence, seems to confirm the complementary association between independence and accountability of regulatory and supervisory agencies.

\footnotetext{
${ }^{18}$ However, these results have to be taken with some caution, because the significance of the correlation coefficients may be flawed by the fact that we have only 17 observations for the BCP index when supervisory functions are separated and the non-normality hypothesis on them cannot be rejected at all conventional levels of confidence by a Shapiro-Wilk test.
} 
Figure 7. Interdependence of BCP and Transparency in Accountability Indices

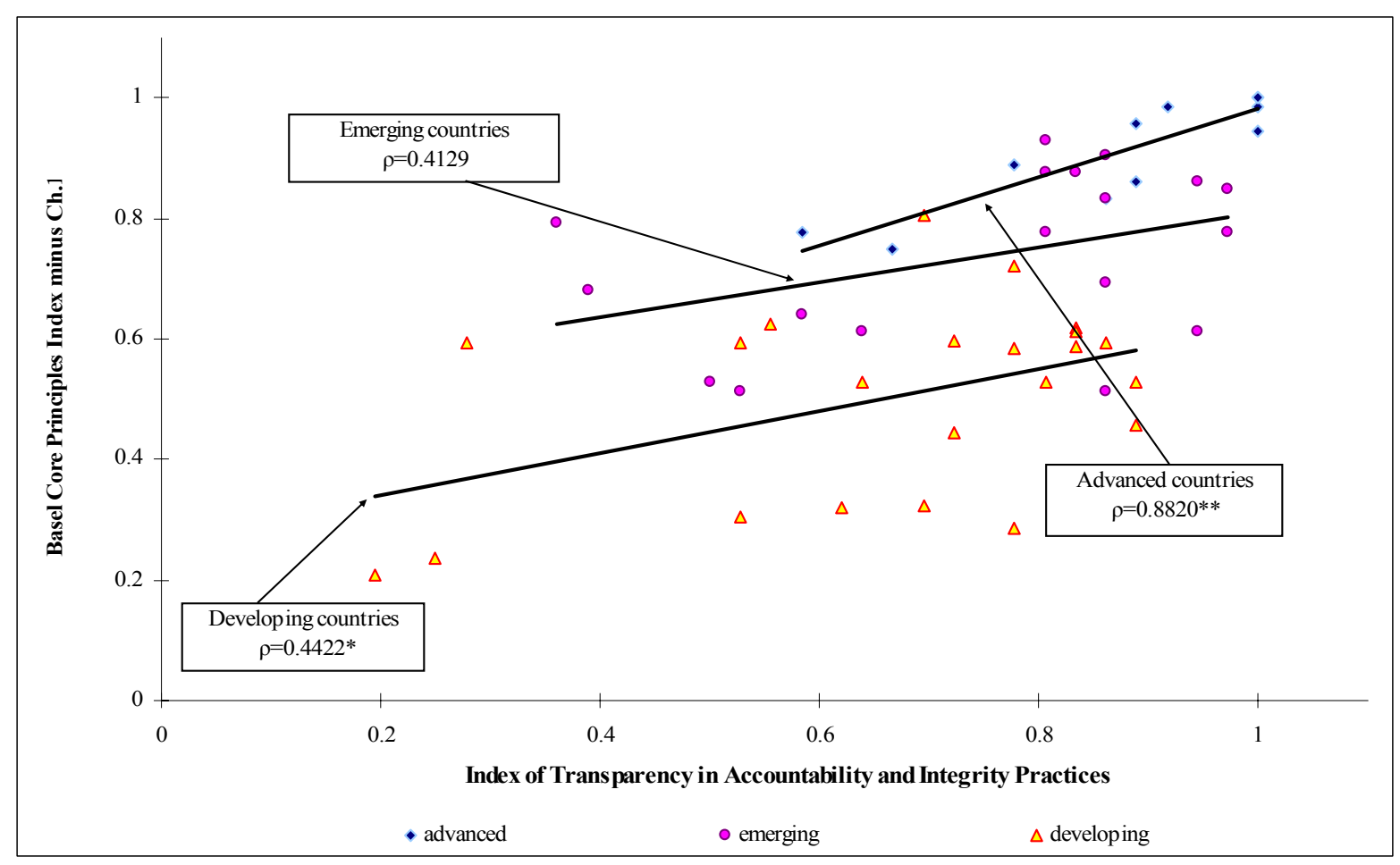

Source: authors' calculations.

*(**) Statistically significant at the 95 (99) percent level of confidence.

\section{Conclusions}

This paper has presented an analysis of the assessments of BCP and transparency requirements in banking supervision, and has studied the relationship between the quality of banking supervision and aspects of governance of the banking supervisors. Our empirical analysis is based on quantitative indices derived from the assessments of the $\mathrm{BCP}$ and the MFP Transparency Code on banking supervision.

The best $\mathrm{BCP}$ scores are in the preconditions for effective banking supervision, and the licensing process and approval for changes in banks' structure, indicating that a good degree of compliance has already been achieved in the "framework" for supervision. However, banking supervisors' compliance with the operational independence principle was found to be among the least fully compliant principle assessed: this indicates that there is scope for strengthening the supervisors' independence, especially from political interference.

The two weakest areas of the $\mathrm{BCP}$ are related to the setting of prudential regulations and requirements (chapter 3 ) and the formal power for supervisors to take adequate measures when banks fail to meet prudential requirements or violate any other regulation (chapter 6); this suggests that RSA preventive and remedial powers should be substantially improved, and that more human and financial resources are needed in these areas. The excellent performance of South-East Asia and the Pacific in the area of remedial measures for banks 
not meeting the requirements (chapter 6) probably stems from the stronger sanctioning powers given to bank supervisors after the 1997-98 financial crisis.

With respect to transparency requirements in banking supervision, these are more likely to be fulfilled (and scored as fully observed) than BCP requirements, probably owing to the fact that it is easier and cheaper to disclose information than build up a regulatory framework with adequate expertise and resources to satisfy $\mathrm{BCP}$ requirements for effective banking supervision.

The degree of full observance for the transparency practices is highest in the areas of formulation and reporting of financial policies (practice 6) and making information on those policies available to the public (practice 7). However, the percentage of not observed practices for accountability and assurance of integrity by financial agencies (practice 8) is twice the average of non-observance for the other three main practices; this high degree of non-observance is especially true for the Western Hemisphere. Also, the high percentage of full observance for South-East Asia and the Pacific in making financial policies available to the public (practice 7) appears consistent with the reforms initiated to improve transparency following the 1997-98 financial crisis.

Europe and Central Asia score the highest BCP and transparency values. This can be attributed in part to the good performance of the several Eastern European transition economies, some of which were at the time of the assessments in the European Union accession process, which fostered a strong economic and legal reform process.

The paper focuses also on the relationship between transparency (and other aspects of governance) of the banking supervisor and the quality of banking supervision. The results show that countries with good governance of the RSA (indicated by high observance of the transparency code) also tend to have good banking supervision (indicated by high compliance with the BCP). This suggests that in most cases these two aspects of the RSA are complementary and may reinforce each other. ${ }^{19}$

A positive significant correlation is found between regulatory governance $(\mathrm{CP} 1)$ and the effectiveness of banking supervision (CP 2-25). This correlation appears to be inversely related to the level of financial development, with the advanced economies exhibiting the lowest and developing countries the highest. Moreover, the analysis of correlation ratios of BCP sub-indices on operational independence (SP 1.2) — which is the least observed among the six SP regarding preconditions for effective banking supervision across the 116 jurisdictions considered-shows that on average the degree of compliance with the BCP improves when operational independence increases. This is particularly true for emerging markets and developing countries, while it does not seem to be the case for advanced economies. This pattern of correlations indicates that the establishment of stronger

\footnotetext{
${ }^{19}$ We do not examine causality between the two; i.e. we do not determine whether good governance leads to high quality of banking supervision or vice-versa. However, the former seems more likely than the latter.
} 
preconditions for effective banking supervision, especially better RSA governance, seems to be more relevant for the achievement of better supervision in developing countries and emerging markets than advanced economies.

The expected positive relationship between transparency and the quality of banking supervision, measured by $\mathrm{BCP}$ compliance, is confirmed by empirical evidence. We find a positive correlation between the sub-index BCP-minus-chapter 1 and the MFP Transparency index across the overall sample of 51 countries, and also within the country groups by stage of financial development, although this correlation is not significant for emerging markets, possibly owing to larger differences within emerging markets, some of which are not so far from advanced countries, while others are closer to the group of developing countries.

This positive correlation is also found when we consider a sub-index of the MFP Transparency Code dealing with transparency practices in accountability and integrity of national supervisory authorities, and the sub-index of BCP-minus-chapter 1 covering all areas of prudential supervision (but not the pre-conditions). This last finding is particularly strong for advanced economies, those with the highest degree of operational independence. These facts suggest that better accountability and integrity practices of the RSA are strongly associated with higher RSA independence, which in turn is associated with better BCP compliance. 


\section{APPENDIX I. CONSTRUCTION OF INDICES OF COMPLIANCE/OBSERVANCE FOR BCP AND MFP TRANSPARENCY CODE IN BANKING SUPERVISION}

The construction of the two indices for every country proceeded as follows:

For each assessed principle/practice of each code, the country's degree of observance was coded as follows:

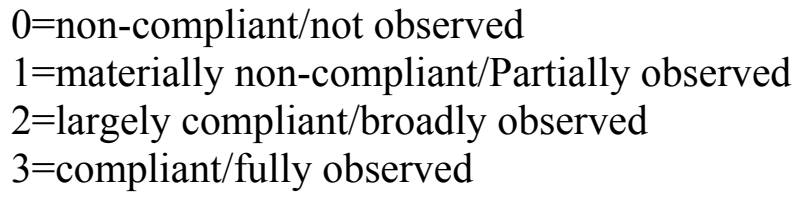

In both codes some principles/practices are not applicable or not assessed. When this occurs a weighting scheme is applied with the rationale to give each country the possibility to achieve the maximum value. The weighting scheme works inside the chapter to which the not applicable principle or practice belongs; the number of possible assessments included in that chapter is divided by the number of actually assessed principles/practices and the result is the weighting coefficient by which each assessed principle has to be multiplied.

For instance, chapter 2 of BCP Code contains 4 possible assessments from CP 2 to CP 5 . Suppose that a country receives for these CP the following assessments:

\section{CP 2 Compliant \\ CP 3 Materially non-compliant \\ CP 4 Largely compliant \\ CP 5 Not applicable}

There are only 3 assessed principles; hence the weighting coefficient for chapter 2 will be $4 / 3=1.333$ and the total score of chapter 2 in this case is $(3 * 1.333+1 * 1.333+2 * 1.333)=8$.

In the exclusive case, in which all principles/practices of a chapter are not applicable or not assessed, the chapter is given the score 0 .

After coding each assessed principle and applying the weighting scheme for not applicable/not assessed principles/practices, the overall index is obtained as the unweighted aggregation of the assessed principles scores, eventually multiplied by the weighting coefficient of their chapter.

The normalized indices are simply obtained by dividing the overall score by the maximum value, 90 (all compliant $=3 * 30 \mathrm{CP}$ ) for the $\mathrm{BCP}$ code and 108 (all fully observed $=3 * 36$ practices) for the MFP Transparency Code. 


\section{REFERENCES}

Arnone, Marco, Bernard J. Laurens, and Jean-François Segalotto (2006), "Measures of Central Bank Autonomy: Empirical Evidence for OECD and Developing Countries, and Emerging Market Economies," IMF Working Paper, No. 228/06.

Arnone, Marco and Eleni Iliopulos (2007), The Cost of Corruption - Economic, Institutional and Social Effects, Vita e Pensiero (Milan: Vita e Pensiero).

Barth, James R., Gerard Caprio, and Ross Levine (2001a), "The Regulation and Supervision of Banks around the World: A New Database," p. 183-250, in Litan, R. and Herring, R. Brookings-Wharton Papers on Financial Services, (Washington DC: Brooking Institution Press).

Barth, James R., Gerard Caprio, and Ross Levine (2001b), "Bank Regulation and Supervision: What Works Best?” World Bank Policy Research Working Paper 2725.

Barth, James R., Gerard Caprio, and Ross Levine (2005), Rethinking Bank Regulation: Till Angels Govern, New York: Cambridge University Press.

Basel Committee on Banking Supervision (1997), "Core Principles for Effective Banking Supervision," September (Basel: Bank for International Settlements), available on the web at http://www.bis.org/publ/bcbs30a.htm.

Basel Committee on Banking Supervision (1999), "Core Principles Methodology," October, (Basel: Bank for International Settlements), available on the web at http://www.bis.org/publ/bcbs61.htm.

Beck, Thorsten, Asli Demirguc-Kunt, and Ross Levine (2003), "Bank Supervision and Corporate Governance," NBER Working Paper, No. 9620.

Briault, Clive, Andrew Haldane, and Mervyn King (1996), "Independence and Accountability," in Towards More Effective Monetary Policy, edited by Iwao Kuroda, (London: MacMillan Press Ltd.).

Das, Udaibir S. and Marc G. Quintyn (2002), “Crisis Prevention and Crisis Management: The Role of Regulatory Governance," IMF Working Paper 02/163.

Das, Udaibir S., Marc Quintyn, and Kina Chenard (2004), "Does Regulatory Governance Matter for Financial System Stability?” IMF Working Paper, No. 04/89.

De Haan, Jakob, Friedrich Amtenbrink, and Sylvester C.W. Eijffinger (1999), "Accountability of Central Banks: Aspects and Quantification," Banca Nazionale del Lavoro Quarterly Review, No. 209, p. 169-193. 
Eijffinger, Sylvester C.W., Marco Hoeberichts, and Eric Schaling (2000), “A Theory of Central Bank Accountability," CERP Discussion Paper 2354.

Eijffinger, Sylvester C.W. and Jakob de Haan (1996), The Political Economy of Central Bank Independence, International Financial Section, Department of Economics, Princeton University.

Hardy, Daniel C. (2006), "Regulatory Capture in Banking,” IMF Working Paper 06/34.

Hüpkes, Eva, Marc Quintyn, and Michael Taylor (2005), “The Accountability of Financial Sector Supervisors: Principles and Practices," IMF Working Paper 05/51.

International Monetary Fund (1999), Code of Good Practices on Transparency of Monetary and Financial Policies, September (Washington, D.C., International Monetary Fund), available on the web at http://www.imf.org/external/np/mae/mft/code/index.htm.

International Monetary Fund and World Bank (2002), "Implementation of the Basel Core Principles for Effective Banking Supervision, Experiences, Influences, and Perspectives," IMF and World Bank Background Paper.

Lastra, Rosa M. and Geoffrey Wood (1999), "Constitutional Approach to Central Bank Independence," Central Banking, Vol. X, No. 3, p. 34-39.

Lybek, Tonny (1998), "Elements of Central Bank Autonomy and Accountability," MAE/IMF Operational Paper, 98/1, Washington DC, International Monetary Fund.

Quintyn, Marc and Michael Taylor (2002), "Regulatory and Supervisory Independence and Financial Stability," IMF Working Paper 02/46.

Stigler, George (1971), "The Theory of Economic Regulation,” Bell Journal of Economics and Management Science, Vol. 6, No. 2, p. 114-141.

Sundararajan V., Udaibir S. Das and Polamen Yossifov (2003), "Cross-Country and CrossSector Analysis of Transparency of Monetary and Financial Policies," IMF Working Paper 03/94. 